\title{
Sweet Corn Sentinel Monitoring for Lepidopteran Field-Evolved Resistance to Bt Toxins
}

\author{
G. P. Dively, ${ }^{1,23}$ T. P. Kuhar, ${ }^{2, \ominus}$ S. Taylor, ${ }^{3}$ H. B. Doughty ${ }^{4}{ }^{4}$ K. Holmstrom, ${ }^{5}$ D. Gilrein, ${ }^{6}$ \\ B. A. Nault, ${ }^{7}$ J. Ingerson-Mahar, ${ }^{8}$ J. Whalen, ${ }^{9}$ D. Reisig, ${ }^{10,0}$ Daniel L. Frank, ${ }^{2}$ \\ S. J. Fleischer, ${ }^{11}$ David Owens, ${ }^{12}$ C. Welty, ${ }^{13}$ F. P. F. Reay-Jones, ${ }^{14,}{ }^{\circ}$ P. Porter, ${ }^{15}$ \\ J. L. Smith, ${ }^{16, \oplus}$ J. Saguez, ${ }^{17, \oplus}$ S. Murray, ${ }^{18}$ A. Wallingford, ${ }^{19}$ H. Byker, ${ }^{20}$ B. Jensen, ${ }^{21}$ \\ E. Burkness, ${ }^{22}$ W. D. Hutchison, ${ }^{22}$ and K. A. Hamby ${ }^{1}$
}

'Department of Entomology, University of Maryland, College Park, MD, '2Department of Entomology, Virginia Tech, Blacksburg, VA, ${ }^{3}$ Department of Entomology, Virginia Tech, Suffolk, VA, ${ }^{4}$ Virginia Tech ESAREC/Entomology, Painter, VA, ${ }^{5}$ Rutgers Pest Management, New Brunswick, NJ, ${ }^{6}$ LIHREC, Cornell University, Riverhead, NY, 'Department of Entomology, Cornell AgriTech, Geneva, NY, ${ }^{8}$ Rutgers Pest Management, Alloway, NJ, ${ }^{9}$ Private IPM Consultant, Millington, MD, ${ }^{10}$ Department of Entomology and Plant Pathology, NC State University, Plymouth, NC, "'Department of Entomology, Penn State University, University Park, PA, ${ }^{2}$ University of Delaware Cooperative Extension, Carvel REC, Georgetown, DE, ${ }^{13}$ Rothenbuhler Lab, Ohio State University, Columbus, $\mathrm{OH},{ }^{14}$ Pee Dee Research and Education Center, Clemson University, Florence, SC, ${ }^{15}$ Department of Entomology, Texas A\&M University, AgriLife Research and Extension Center, Lubbock, TX, ${ }^{16}$ Field Crop Pest Management, University of Guelph, Ridgetown, Ontario NOP 2C0, Canada, ${ }^{17} \mathrm{CEROM}$, 740 Chemin Trudeau, Saint-Mathieu-de-Beloeil, Quebec J3G 0E2, Canada, ${ }^{18}$ Perennia Food and Agriculture, Kentville, Nova Scotia B4N 1J5, Canada, ${ }^{19}$ University of New Hampshire Cooperative Extension, Durham, NH, ${ }^{20}$ Department of Plant Agriculture, University of Guelph, Winchester, Ontario KOC 2K0, Canada, ${ }^{21}$ Department of Entomology, University of Wisconsin, Madison, WI, ${ }^{22}$ Department of Entomology, University of Minnesota, St. Paul, MN, and ${ }^{23}$ Corresponding author, e-mail: galen@umd.edu

Subject Editor: Aaron Gassmann

Received 1 July 2020; Editorial decision 14 October 2020

\begin{abstract}
As part of an insect resistance management plan to preserve Bt transgenic technology, annual monitoring of target pests is mandated to detect susceptibility changes to Bt toxins. Currently Helicoverpa zea (Boddie) monitoring involves investigating unexpected injury in Bt crop fields and collecting larvae from non-Bt host plants for laboratory diet bioassays to determine mortality responses to diagnostic concentrations of Bt toxins. To date, this monitoring approach has not detected any significant change from the known range of baseline susceptibility to Bt toxins, yet practical field-evolved resistance in $H$. zea populations and numerous occurrences of unexpected injury occur in Bt crops. In this study, we implemented a network of 73 sentinel sweet corn trials, spanning 16 U.S. states and 4 Canadian provinces, for monitoring changes in $H$. zea susceptibility to Cry and Vip3A toxins by measuring differences in ear damage and larval infestations between isogenic pairs of non-Bt and Bt hybrids over three years. This approach can monitor susceptibility changes and regional differences in other ear-feeding lepidopteran pests. Temporal changes in the field efficacy of each toxin were evidenced by comparing our current results with earlier published studies, including baseline data for each Bt trait when first commercialized. Changes in amount of ear damage showed significant increases in $H$. zea resistance to Cry toxins and possibly lower susceptibility to Vip3a. Our findings demonstrate that the sentinel plot approach as an in-field screen can effectively monitor phenotypic resistance and document field-evolved resistance in target pest populations, improving resistance monitoring for Bt crops.
\end{abstract}

Key words: Bt toxin, insect resistance monitoring, sentinel sweet corn

Transgenic corn expressing insecticidal toxins sourced from Bacillus thuringiensis (Bt) bacteria was first introduced in 1996 and now makes up over $80 \%$ of corn plantings in the United States (USDA ERS 2019). The widespread use of Bt crops reduces yield loss and insecticide use, promotes biocontrol services, provides regional suppression of pest populations, and delivers economic benefits for growers (Carrière et al. 2003, Wu et al. 2008; Hutchison et al. 2010; Bell et al. 2012; Edgerton et al. 2012; Lu et al. 2012; NASEM 2016; Perry et al. 2016; Dively et al. 2018; Romeis et al. 2019). Because this technology helps control the major lepidopteran pests of corn in the 
United States, specifically, corn earworm/bollworm [Helicoverpa zea (Boddie) Lepidoptera: Noctuidae] (Buntin et al. 2004, Reay-Jones and Reisig 2014), European corn borer [Ostrinia nubilalis (Hübner) Lepidoptera: Crambidae] (Koziel et al. 1993), and fall armyworm [Spodoptera frugiperda (J.E.Smith) Lepidoptera: Noctuidae] (Buntin et al. 2004, Reay-Jones et al. 2016), it has become the foundation of insect pest management. However, the widespread use of Bt crops and constitutive expression of Bt toxins within the plant exert high selection pressure on the target insects, facilitating the evolution of pest resistance.

Because resistance is the major threat to the sustainability of $\mathrm{Bt}$ transgenic technology, commercial registration of Bt crops with the U.S. Environmental Protection Agency (EPA) requires an insect resistance management (IRM) plan. Ideally, this includes a high-dose refuge strategy, wherein the Bt toxin is expressed at a high enough dose that offspring resulting from matings between susceptible and resistant individuals will not survive on the Bt crop, and untreated refuges are planted to provide susceptible individuals that can mate with resistant individuals that survive the Bt crop (Gould 1998, Tabashnik et al. 2013). To further combat resistance development, pyramided hybrids with multiple toxins that target the same pest have been developed (Roush 1998, Carrière et al. 2016). Due to low compliance in planting and maintaining untreated refuge (Reisig 2017), registrants have also introduced seed mix refuges with non-Bt plants premixed with pyramided Bt hybrids (Davis and Onstad 2000, Carroll et al. 2012). In addition to these IRM approaches, EPA requires registrants to annually monitor susceptibility of target insect species to Bt toxins in order to detect changes in field efficacy. For example, $H$. zea unexpected injury (UXI) in Bt crop fields is investigated and registrants also conduct focused field collections of larvae from non-Bt host plants in the southern United States for laboratory bioassays to determine mortality responses of $\mathrm{F}_{1}$ populations to diagnostic concentrations of the toxins. To date, registrants have not reported any significant change from the known range of baseline susceptibility to Bt toxins in $H$. zea populations (USEPA 2020), yet practical field-evolved resistance and numerous occurrences of unexpected injury occur in Bt field corn and cotton.

Published studies provide strong evidence of field-evolved resistance to the Cry toxins in Bt crops, resulting in practical consequences for control of several major lepidopteran pests (Tabashnik and Carriére 2017). Helicoverpa zea populations have evolved resistance to Cry1Ab, Cry2Ab2, Cry1A.105, and Cry1Ac (Reisig and Reay-Jones 2015, Dively et al. 2016, Yang et al. 2017, Reisig et al. 2018, Bilbo et al. 2019, Kaur et al. 2019); S. frugiperda to Cry1F (Blanco et al. 2010, Storer et al. 2010, Farias et al. 2014, Huang et al. 2014, Li et al. 2016, Omoto et al. 2016); and western bean cutworm [Striacosta albicosta (Smith) (Lepidoptera: Noctuidae) to Cry1F (Ostrem et al. 2016, Smith et al. 2017). There has been no evidence of any shift in O. nubilalis susceptibility to the expressed toxins, except for a recent study documenting the first case of practical resistance to Cry1F corn in the Province of Nova Scotia, Canada (Smith et al. 2019). So far, Bt corn continues to provide highly effective control against $O$. nubilalis in all other corn production areas of North America; however, action must be taken to avoid further evolution of resistance in this species.

A different Bt toxin, Vip3A, takes advantage of a novel insecticidal protein class and exhibits a wide spectrum of activity against lepidopteran pests (Estruch et al. 1996). Currently, pyramided with Cry 1 and Cry 2 toxins in Bt corn and Bt cotton, Vip3A provides exceptional control of most lepidopteran pests of corn, and unlike Cry toxins, expresses a near high dose against $H$. zea (Burkness et al. 2010, Yang et al. 2015, Marques et al. 2019). Although Vip3A toxin shows no or weak cross resistance with the Cry toxins (Tabashnik and Carriere 2020), there is concern that this important Bt trait may be compromised more quickly if seed blends of Vip3A-expressing corn become available in the southern United States, where H. zea populations overwinter and are exposed to cotton varieties expressing Vip3A and Cry toxins (Reisig and Kurtz 2018). Already, there is evidence of higher infestations and low-level tolerance of H. zea populations in Cry1 Ab + Cry1F + Vip3A pyramided corn in Texas (Yang et al. 2019, Yang et al. 2020). To preserve the efficacy of this toxin, changes in susceptibility must be detected early and quickly mitigated.

A July 2018 Scientific Advisory Panel (SAP) met to discuss issues involving lepidopteran pest resistance to Bt crops and provide recommendations to EPA. The panel recommended that seed blends of Vip3A corn be prohibited in the southern regions of the United States, and reported on many limitations and challenges in the current resistance monitoring approach (USEPA 2018). Specifically, there is no clear definition of resistance or UXI thresholds to trigger mitigation action, and random sampling of target pest populations does not track susceptibility over time. Although laboratory diet bioassays can be powerful tools for understanding resistance and establishing heritability, they necessitate large collections of resistant individuals from the field and laboratory rearing to at least an $F_{1}$ generation so that larval development phenotypes can be measured. With smaller field collections, further rearing may be necessary to produce sufficient individuals for an assay, which often eliminates resistant genotypes due to fitness problems (USEPA 2018). Indeed, the SAP stated that 'these [laboratory diet] assays delay reporting of resistance occurrences and are too variable for non-high dose pests, such as H. zea' (USEPA 2018). To address these issues, the SAP recommended measures to improve the current sampling and bioassay protocol, including standardized diet bioassays, targeted sampling of UXI Bt corn, and cotton fields, as well as to develop and integrate new molecular detection technologies. For non-high-dose pests, small changes in susceptibility can result in increased injury/damage to the crop and assays must be sensitive enough to avoid false negatives (Andow et al. 2016). Although there were reservations as to whether sentinel plots can detect resistance quickly enough for mitigation (USEPA 2018), sentinel plots diagnosed increasing damage over time before diet bioassays could successfully be conducted to confirm resistance in H. zea (Dively et al. 2016).

Sentinel Bt sweet corn can be used as a field-based diagnostic to monitor resistance in a target insect population to Bt toxins (Venette et al. 2000). Relative to the sample sizes required for detecting resistant larvae using diagnostic dose laboratory bioassays, in-field monitoring likely detects rare resistant phenotypes earlier (Venette et al. 2000). Although this approach directly measures phenotypic resistance, consistent declines in field efficacy of the Bt crop observed over time offer evidence of field-evolved or 'practical' resistance (Moar et al. 2008; Tabashnik et al. 2009, 2013, 2014). Dively et al. (2016) used this reasoning to provide evidence for the evolution of 'practical' resistance in H. zea to Cry1Ab and Cry1A.105+Cry2Ab2 toxins, comparing $\mathrm{H}$. zea damage in paired $\mathrm{Bt}$ and non-Bt sentinel plots over two decades in Maryland and demonstrating decreasing $H$. zea susceptibility to Bt sweet corn since its commercial introduction in 1996. Despite the advantages of in-field monitoring, including ease of use, this approach to resistance monitoring has not yet been widely adopted. 
To encourage adoption of in-field resistance monitoring and facilitate detection of changes in $H$. zea susceptibility to Bt toxins, we continued the Dively et al. (2016) study, implementing a large-scale monitoring network of sweet corn sentinel trials from 2017 to 2019. The network was designed to examine changes in H. zea susceptibility to toxins expressed in different Bt sweet corn hybrids, with particular focus on the more efficacious Vip3A toxin. It also provided a means to simultaneously monitor for susceptibility changes and regional differences in O. nubilalis and S. frugiperda populations. To show overall changes in field efficacy of each Bt toxin over time, we compared the monitoring network results with earlier reported data from sentinel monitoring in Maryland (Dively et al. 2016) and other states (Burkness et al. 2010, Shelton et al. 2013). Our findings demonstrate the utility of the sentinel plot approach and enable improvements in the design of resistance monitoring for Bt crops.

\section{Methods and Materials}

\section{Sentinel Locations}

The monitoring network consisted of paired sentinel plots of $\mathrm{Bt}$ and non-Bt sweet corn hybrids, with 18 locations in 9 U.S. states (DE, MD, NC, NJ, NY, OH, PA, VA, and WV) established in 2017 and 2018. We expanded the network in 2019 to include 30 locations in 16 U.S. states (DE, MD, ME, MN, NC, NH, NJ, NY, OH, PA, SC, TX, VA, VT, WI, and WV) and 4 eastern Canadian provinces (New Brunswick, Nova Scotia, Ontario, and Quebec) (Fig. 1). Sentinel locations varied with respect to typical lepidopteran population densities and overwintering success. About one half of the trials were located too far north to allow successful $H$. zea overwintering. At these locations, infestation in sweet corn results from migrant moths carried northward on storm fronts from the south, where they were probably subjected to previous selection pressure in Bt corn or Bt cotton. These peripheral $H$. zea populations occasionally exhibit genetic differentiation (Perera et al. 2020), though evidence largely indicates $H$. zea populations are genetically diverse and panmictic with low genetic variability between populations (Seymour et al. 2016). Sentinel plots were established later in the normal planting period (mid-May to early July depending on region) and timed such that the silking period coincided with anticipated peak $H$. zea moth activity to maximize pressure. In total, 73 sentinel trials were planted over the $3 \mathrm{yr}$ of the monitoring network (Supp Table 1 [online only]).

\section{Hybrids and Plot Layout}

Sentinel plots consisted of five sweet corn hybrids: 1) Attribute BC0805 expressing Cry1Ab, 2) Attribute II Remedy expressing $\mathrm{Cry} 1 \mathrm{Ab}$ and Vip3A, and 3) their non-Bt isoline Providence

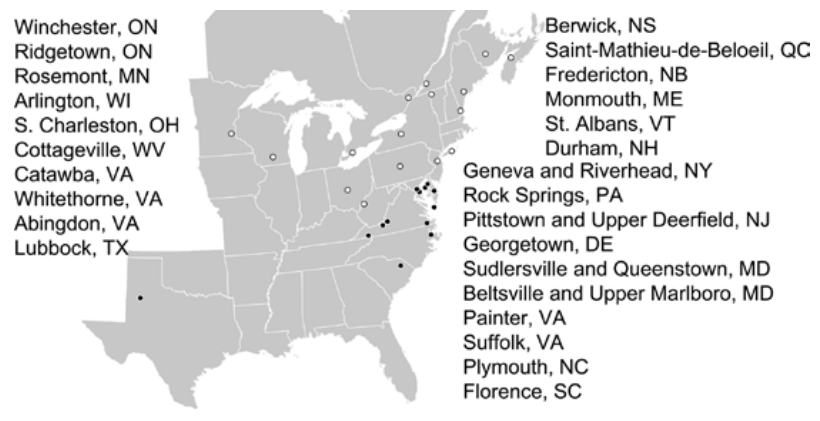

Fig. 1. Map of 2019 sweet corn sentinel monitoring network locations. White points indicate locations where there is likely no successful overwintering of Helicoverpa zea populations, dark points indicate successful overwintering.
(Syngenta); as well as 4) Performance Series Obsession II expressing Cry1A.105+Cry2Ab2, and 5) its non-Bt isoline Obsession I (Seminis). At each trial location, single or replicate plots of each $\mathrm{Bt}$ hybrid were planted at the same time and arranged side-by-side with their non-Bt isolines. One exception in 2017 is that both Obsession hybrids were planted only in Maryland. Typically, only one planting of the five hybrids occurred per location each year; however, two and sometimes three plantings spaced $10 \mathrm{~d}$ apart were established at different locations in Maryland from mid-June to early August. Each plot ranged in size from four to eight rows (0.9 m apart) 15to $60-\mathrm{m}$ long and was maintained according to commercial sweet corn production practices, except no foliar insecticides were applied. Irrigation was applied at most trial locations to ensure normal plant growth. Although neither Bt protein content nor expression levels were measured, production best management practices were followed to avoid crop stress and sampling occurred at similar crop phenology, improving the consistency of toxin expression (Trtikova et al. 2015) in our trials.

\section{Ear Sampling}

In order to maximize ear damage and best capture the number of surviving larvae, ears were examined for kernel damage and larval infestation during the milk stage 21-25 d after silk emergence, which coincided with anticipated delayed development of $H$. zea larvae in Bt plots. Samples of 50 and 100 ears were examined from the center rows of each non-Bt and Bt plot, respectively. Data were recorded from ears in situ or samples of ears were removed from plants and then processed at a more convenient location next to the field. Each ear was slowly opened at the tip to avoid losing small larvae, and husked down all the way to expose the base of ear if there were signs of feeding injury on husk leaves and shank of the ear, which is particularly characteristic of $S$. frugiperda and O. nubilalis injury.

Ear damage was assessed according to the methods used by Dively et al. (2016). A standardized data sheet and sampling protocol were used at all locations to record kernel damage and larval survival on a per ear basis. The spatial pattern of kernel injury caused by each species was tallied with the aid of a standard pencil eraser (cross-section $\sim 0.5 \mathrm{~cm}^{2}$ ) as a visual reference and consolidated to estimate the total $\mathrm{cm}^{2}$ of kernel surface area consumed. For ears with very minor feeding injury $\left(<0.5 \mathrm{~cm}^{2}\right)$ on a few kernels on the ear tip, kernel damage was recorded as $0.2 \mathrm{~cm}^{2}$; otherwise, kernel area consumed $\geq 0.5 \mathrm{~cm}^{2}$ was recorded to the nearest $0.5 \mathrm{~cm}^{2}$. The location of damage was recorded as ear tip, upper half of ear, lower half of ear or combinations of the three. Feeding injury on the husk leaves and ear shank without kernel injury was also recorded. When S. frugiperda larvae were found together with $H$. zea, their damage was differentiated by the feeding pattern and location of kernel injury. Individuals recording data were trained to visually estimate kernel damage and checked for consistency to ensure accurate data.

The number and instar of surviving larvae was recorded per individual ear for each lepidopteran species. If O. nubilalis tunneling was observed, the ear was split open to record the instar if the larva was present. Because ear sampling was timed to account for delayed larval development in the Bt plots, many non-Bt ears had significant kernel injury caused by $H$. zea that reached the prepupal stage and exited the ear. For these ears, we recorded a sixth instar if $>6 \mathrm{~cm}^{2}$ of kernel area was consumed, with characteristic deposits of frass on the upper ear and evidence of an exit hole. In less common cases, two exited sixth instars were recorded if kernel area consumed $\geq 12 \mathrm{~cm}^{2}$ and there was evidence of separate feeding patterns on opposite sides of the ear. 
Although we did not confirm Bt toxin expression in most cases, some sites used commercially available ELISA strip tests to check for the presence of Vip3A expression in green husk tissue when UXI occurred in Vip3A hybrids and data from nonexpressing ears were removed.

\section{Plant Sampling}

Because kernel feeding and the presence of O. nubilalis can be obscured by H. zea kernel injury, whole plants were sampled in 2018 and 2019 to further determine regional differences in O. nubilalis infestations and to detect possible unexpected injury in the Bt hybrids. At a subset of trial locations, 50 consecutive plants from the center rows of each hybrid plot were carefully examined for entrance holes and frass around the leaf axil or shank of the ear, as evidence of stalk tunneling.

\section{Data Analysis}

Individual ear data were compiled per trial and summarized for analysis, except for missing data from four trials where weather or agronomic factors prevented normal ear development. The percentage of ears damaged by each species was averaged over the non-Bt hybrids (Providence and Obsession I) for each trial and used to describe pest pressure and differences in infestation over the three monitoring years. The following metrics for each trial were calculated by hybrid for each species: percentage of ears damaged, mean kernel area consumed $\left(\mathrm{cm}^{2}\right)$ per damaged ear, and mean number of larvae per damaged ear. For $H$. zea, we also recorded the percentage of late instar (fourth, fifth, and sixth) larvae. For H. zea response variables, we performed either an ANOVA using the Proc Mixed model or GENMOD Poisson regression of SAS Version 9.4 (SAS 2001), depending on the data distribution. Each analysis treated year as a fixed factor, trial location as a random effect, and adjusted variance according to the number of trials per year, after data transformations were made for lack of normality. Overall means were calculated by averaging over all trials by year. All presented means and SEs were back transformed, and confidence limits were calculated from un-transformed data.

Trends in amount of damage (evidence of changes in H. zea susceptibility) were further illustrated by comparing the ear damage and larval densities from the monitoring network with the same metrics reported from earlier published studies, including baseline data when each Bt trait was first commercialized. For the Cry1 Ab toxin, 2017-2019 ear damage data were averaged to represent the current field damage and compared with ear damage reported on for $21 \mathrm{yr}$ (1996-2016) of sentinel monitoring in Maryland (Dively et al. 2016). We arbitrarily divided the latter dataset into three time periods and computed averages for years 1996-2003 (representing baseline field damage), 2004-2010, and 2011-2016. A similar timeline was used for H. zea susceptibility to the Cry1A.105+Cry2Ab2 toxins, comparing 2017-2019 ear damage with earlier reported ear damage from 7 yr (2010-2016) of sentinel monitoring data in Maryland (Dively et al. 2016) and data extracted from field trials conducted in NY, MN, OH, and GA (Shelton et al. 2013). We averaged the early reported data over two time periods: 2010-2013 (representing baseline field damage) and 2014-2016. For Cry1Ab and Vip3A toxins, published studies on field efficacy reported virtually $100 \%$ control of $H$. zea during the first $8 \mathrm{yr}$ (2007-2014), it was commercially available for academic trials (Dively et al. 2016, Burkness et al. 2010). We averaged all reported data on damaged ears during that time period to represent baseline pest control for the Vip3A toxin. To elucidate changes in H. zea susceptibility to Vip3A, we compared the baseline damage with the average ear damage during each year of the monitoring network.

The percentage of damaged ears was visualized with boxwhisker plots to display differences between paired Bt and non-Bt sentinel trials over each time period, relative to the baseline damage experienced by each Bt toxin. Plots depict the 25 and $75 \%$ percentile range of individual data, median, mean $\pm \mathrm{SE}$, and connecting lines link each paired trial. The mean difference in percentage ear damage between $\mathrm{Bt}$ and non-Bt paired plots and the $95 \%$ confidence limits were calculated for each time period. We tested for significant changes in amount of damage indicated by mean differences between time periods using a two sample $t$-test (assuming uneven variances and a one tailed hypothesis). We assumed that a significant increase in ear damage over time was sufficient to confirm fieldevolved resistance as defined in Tabashnik et al. $(2009,2013,2014)$. We also estimated phenotypic frequency of resistance as the ratio of mean densities of $H$. zea larvae found in Bt ears relative to mean larval densities in non-Bt ears, according to Venette et al. (2000). For computing these frequencies, we pooled all larval density data from each time period, corrected for sample size differences, and assumed that any live larvae (regardless of instar) associated with kernel damage in a $\mathrm{Bt}$ ear indicates some degree of resistance to the expressed toxins. Although this metric overestimates the frequency of resistance alleles and accuracy is dependent on sample size, this ratio provides a useful relative measure of changes in the frequency of $H$. zea that can survive in $B t$ ears in the field.

\section{Results}

\section{Ear Damage Levels in non-Bt Sweet Corn}

Mean percentages of non-Bt ears damaged by H. zea, O. nubilalis, and $S$. frugiperda are given in Supp Table 1 (online only). Helicoverpa $z e a$ populations were very high at most locations each year, causing significant kernel injury in $>75 \%$ of the non-Bt ears in 50 of the 69 trials. Highest infestations typically occurred at sites where overwintering occurs (Fig. 1, Supp Table 1 [online only]), particularly, DE, MD, and NJ, where $>90 \%$ of the ears were damaged in all years. Lowest infestations were recorded in 2019 at trials in $\mathrm{MN}$, NH, NY, WI, and the Canadian provinces. Of the 15 locations with sentinel trials repeated each year, ear damage levels between years varied widely, particularly where $H$. zea did not overwinter. For example, the percentage of ears damaged at Geneva, NY, was less than $12.5 \%$ in 2017 compared with $99.5 \%$ in 2018 and $49.6 \%$ in 2019. At this location, pheromone trap captures in 2018 recorded a major influx of H. zea moths exceeding 100 per night about 6 $\mathrm{d}$ after silking, compared with significantly lower moth captures in 2017 and 2019. Although harvest dates ranged from mid-July to mid-October, ear infestations of $H$. zea were not consistently related to planting dates or timing of silking. For example, four separate plantings were established at Upper Marlboro, MD in 2017, with harvest dates ranging from 14 July to 28 September, yet $H$. zea damaged $98 \%$ of the non-Bt ears in all plantings.

Ear infestations of $S$. frugiperda, as well as observed injury during the vegetative stages, were reported in only 16 of the 69 trials, with the highest percentage of non-Bt ears damaged at Suffolk, VA $(68 \%)$ and Painter, VA (36\%) in 2017; Painter, VA (9\%) in 2018; and Lubbock, TX (38\%), and Painter, VA (18\%) in 2019. All other locations did not observe any $S$. frugiperda damage or reported $<5 \%$ of the ears damaged. Ostrinia nubilalis feeding injury in non-Bt ears was reported in only 26 of the 69 trials. Infestations were very low ( $<5 \%$ of ears damaged), except for several locations that consistently 
reported ear damage each year. Ostrinia nubilalis damaged 27, 8, and $26 \%$ of the ears at Painter, VA; 24, 6, and $6 \%$ at Riverhead, NY; and 8,4 , and $21 \%$ at Geneva, NY, during 2017, 2018, and 2019, respectively. Three other locations with relatively high $O$. nubilalis infestations in 2019 included Pittstown, NJ (46\%), Winchester, Ontario $(37 \%)$, and Saint-Mathieu-de-Beloeil in southern Quebec $(21 \%)$.

\section{Helicoverpa zea Damage to Bt hybrids During 2017-2019}

Damage to Bt sweet corn hybrids is compared to their non-Bt isolines using percentage of ears damaged by $H$. zea, instar age and density of larvae, and kernel area consumed (Table 1). Levels of ear damage and larval infestations in both non-Bt hybrids were similar and did not significantly change by year. Overall, 86.7 and $80.6 \%$ of Obsession I and Providence ears were damaged, with 1.25 and 1.31 larvae per damaged ear, 6.3 and $7.0 \mathrm{~cm}^{2}$ of kernel area consumed, and 75.6 and $73.4 \%$ infested with late instars, respectively. Toxins expressed by the three Bt hybrids differed in $H$. zea ear damage and larval infestation. Cry1Ab expressing sweet corn provided the lowest level of control, with overall $72.3 \%$ of the ears damaged compared to $78.7 \%$ damaged in the adjacent non-Bt plots. Although the difference is significant $\left(F_{(1,84)}=5.45\right.$, $P=0.022$ ), only $8.1 \%$ of the ear damage was reduced by Cry $1 \mathrm{Ab}$. In fact, 28 out of 69 trials reported an equal or higher percentage of damaged ears in the Cry1 Ab plots compared with damage levels in the isoline. The proportion of Cry1 Ab ears damaged did not significantly change over the 3 yr. However, kernel consumption and larval infestations significantly increased from 2017 to 2019. The amount of kernel area consumed per damaged Cry1Ab ear increased from 3.7 to $5.3 \mathrm{~cm}^{2}\left(F_{(2,31)}=3.35, P=0.048\right)$; number of larvae per damaged ear increased from 1.07 to $1.45\left(F_{(2,31)}=3.32\right.$, $P=0.049)$; and percentage of late instars increased from 41.9 to $61.5 \%\left(F_{(2,31)}=3.58, P=0.040\right)$. More importantly, overall infestation levels per damaged Cry1Ab ear averaged 1.29 larvae compared with 1.31 larvae in isoline ears, indicating that many H. zea larvae are able to tolerate Cry1 $\mathrm{Ab}$ expression.
Differences in ear damage measurements between Cry1A.105+Cry2Ab2 sweet corn and its isoline were consistently greater than those between Cry1Ab sweet corn and its isoline. Averaged over years, $73.5 \%$ of the Bt ears were damaged compared with $86.7 \%$ of the non-Bt ears damaged in the adjacent isoline plots, and reductions in kernel feeding and larval development were about double that of Cry1Ab ears. Nonetheless, the dual toxin expression provided only $15.2 \%$ field efficacy, calculated by the difference in percentage damaged by $H$. zea in Bt and non-Bt ears divided by the percentage damaged in non-Bt ears times 100. An overall average of 1.12 larvae per ear was found alive in the Cry1A.105+Cry2Ab2 hybrid, which is not significantly different $\left(F_{(2,16)}=0.33, P=0.72\right)$ from the 1.25 larvae per isoline ear. There were no year-to-year differences in the incidence and severity of $H$. zea ear damage in the Cry1A.105+Cry2Ab2 plots $\left(F_{(2,16)}=0.12, P=0.89\right)$; however, the percentage of late instars increased significantly from $41.8 \%$ in 2017 to $81.0 \%$ in $2019\left(F_{(2,16)}=6.24, P=0.010\right)$.

Sweet corn expressing Cry1A+Vip3A toxins provided near 100\% control of $H$. zea during the $3 \mathrm{yr}$ of the monitoring network. Averaged over trials, expression of these toxins reduced the percentage of damaged ears by $99 \%$, compared with the non-Bt isoline. However, results by year show a small but noticeable increase in the number and age of surviving larvae, with the caveat that $\mathrm{Bt}$ expression was often not confirmed. In 2017, only 16 of the 2,941 ears $(0.54 \%)$ sampled in 24 trials exhibited evidence of $H$. zea feeding on the ear tip, averaging $<0.5 \mathrm{~cm}^{2}$ of kernel area consumed per damaged ear. Of these damaged ears, a total of 13 second instars averaging 0.50 per ear were found alive at the ear tip. In 2018, 24 trials recorded a total of 22 ears with $H$. zea damage per 2,676 ears $(0.83 \%)$ sampled, with an average 0.50 larvae and $0.7 \mathrm{~cm}^{2}$ of kernel area consumed per damaged ear. All 33 live larvae associated with the damaged ears were second and third instars. In 2019, the percentage of damaged ears increased slightly, with 32 ears $(0.86 \%)$ damaged per 3,677 ears sampled. However, larval density averaged 1.65 per damaged ear and $31 \%$ of the 29 larvae found were fourth instars. Supp Table 2 (online only) lists the damage and larval density data for those sentinel trials that recorded H. zea damage in the Vip3A expressing ears.

Table 1. Mean $( \pm \mathrm{SD})$ percentage of ears damaged by $H$. zea, density of larvae, amount of kernel area consumed, and percentage of late instars in Bt sweet corn hybrids compared side-by-side to their non-Bt isolines

\begin{tabular}{|c|c|c|c|c|c|}
\hline Hybrid (Bt trait) & $\begin{array}{l}\text { Year (no. of } \\
\text { trials) }\end{array}$ & $\%$ Ears damaged & $\begin{array}{l}\text { Number of larvae per } \\
\text { damaged ears }\end{array}$ & $\begin{array}{l}\text { Kernel consumption per damaged } \\
\text { Bt ear }\left(\mathrm{cm}^{2}\right)\end{array}$ & $\begin{array}{l}\% \text { Late } \\
\text { instars }\end{array}$ \\
\hline \multirow[t]{3}{*}{ Obsession I (non-Bt isoline) } & $2017(6)$ & $95.7 \pm 2.9$ & $1.15 \pm 0.10$ & $6.0 \pm 1.3$ & $84.7 \pm 17.1$ \\
\hline & $2018(15)$ & $87.9 \pm 20.7$ & $1.34 \pm 0.60$ & $6.5 \pm 3.2$ & $61.0 \pm 27.9$ \\
\hline & $2019(30)$ & $76.6 \pm 31.8$ & $1.48 \pm 0.61$ & $6.5 \pm 4.5$ & $81.0 \pm 22.0$ \\
\hline \multirow[t]{3}{*}{ Providence (non-Bt isoline) } & $2017(18)$ & $83.9 \pm 21.9$ & $1.01 \pm 0.44$ & $6.5 \pm 2.8$ & $74.0 \pm 24.4$ \\
\hline & $2018(19)$ & $84.6 \pm 18.6$ & $1.42 \pm 0.39$ & $7.7 \pm 2.7$ & $66.7 \pm 24.6$ \\
\hline & $2019(30)$ & $73.2 \pm 32.9$ & $1.27 \pm 0.49$ & $6.9 \pm 5.5$ & $79.4 \pm 19.3$ \\
\hline \multirow[t]{3}{*}{ BC0805 (Cry1Ab) } & $2017(18)$ & $79.0 \pm 23.3$ & $1.07 \pm 0.62$ & $3.7 \pm 2.0$ & $41.9 \pm 24.7$ \\
\hline & $2018(19)$ & $75.4 \pm 27.8$ & $1.36 \pm 0.36$ & $5.0 \pm 1.9$ & $46.9 \pm 29.5$ \\
\hline & $2019(30)$ & $66.4 \pm 34.3$ & $1.45 \pm 0.78$ & $5.3 \pm 4.9$ & $61.5 \pm 28.7$ \\
\hline \multirow{3}{*}{$\begin{array}{l}\text { Obsession II } \\
\text { (Cry1A.105+Cry2Ab2) }\end{array}$} & $2017(8)$ & $83.2 \pm 17.9$ & $0.88 \pm 0.32$ & $2.3 \pm 1.2$ & $41.8 \pm 22.6$ \\
\hline & $2018(15)$ & $79.5 \pm 23.3$ & $1.28 \pm 0.64$ & $3.8 \pm 1.7$ & $36.5 \pm 31.0$ \\
\hline & $2019(30)$ & $57.8 \pm 35.2$ & $1.18 \pm 0.51$ & $3.9 \pm 3.1$ & $81.0 \pm 31.9$ \\
\hline \multirow[t]{3}{*}{ Remedy (Cry1Ab+Vip3A) } & $2017(24)$ & $0.5 \pm 0.8$ & $0.01 \pm 0.01$ & $0.5 \pm 0.8$ & $0.0 \pm 0.0$ \\
\hline & $2018(24)$ & $0.8 \pm 1.5$ & $0.50 \pm 0.88$ & $0.7 \pm 1.0$ & $0.0 \pm 0.0$ \\
\hline & $2019(31)$ & $0.9 \pm 2.2$ & $1.65 \pm 2.23$ & $0.4 \pm 0.6$ & $47.8 \pm 46.7$ \\
\hline
\end{tabular}

Means are listed by hybrid for each year. Data were averaged from sentinel trials conducted at 15 locations in seven states (NC, VA, WV, MD, DE, NJ, and NY) in 2017; 16 locations in eight states (NC, VA, OH, PA, MD, DE, NJ, and NY) in 2018; and 28 locations in 16 states (TX, SC, NC, VA, MD, WV, OH, DE, PA, NJ, NY, MN, WI, NH, VT, and ME) and four Canadian provinces (Ontario, Quebec, New Brunswick, and Nova Scotia) in 2019. 


\section{Ear Damage by Other Lepidopteran Larvae}

Fourteen of the 69 sentinel trials reported S. frugiperda ear damage in the Bt plots [Supp Table 1 (online only)]. Of these, the Cry1A.105+Cry2Ab2 and Cry1A+Vip3Aa sweet corn provided nearly $100 \%$ control of $S$. frugiperda, whereas the Cry1Ab sweet corn was noticeably less effective, particularly at trial locations with higher infestations in the non-Bt hybrids. For example, the Painter and Suffolk trials in VA consistently reported the highest infestations, with 12 and $21 \%$ of the Cry1Ab ears damaged in 2017, respectively. There were only seven trials reporting evidence of $O$. nubilalis ear damage (mostly <3\%) [Supp Table 1 (online only)] and a few live larvae in Bt hybrids, primarily in the Cry1Ab sweet corn, and at trial locations with the highest infestations in the non-Bt plots. Ear damage by western bean cutworm, S. albicosta Smith, was reported only at the 2019 Saint-Mathieu-de-Beloeil trial in southern Québec, where $11 \%$ of the Cry1Ab ears were infested, while the other hybrids experienced $\leq 3 \%$ ear damage.

\section{Plant Infestations of $O$. nubilalis}

Additional whole plant sampling of each hybrid was conducted at 20 sentinel locations in 2018 and 2019 to further monitor for O. nubilalis. Fifteen trials found either no evidence of O. nubilalis damage or $<5 \%$ of the non-Bt stalks with signs of stalk tunneling. Five trials reported significantly higher levels of plant injury, which corresponded closely with levels of ear damage. The percentage of non-Bt plants with O. nubilalis injury averaged 97\% (2018) and 19\% (2019) at Painter, VA; 8\% (2019) at Riverhead, NY; 27\% (2019) at Berwick, Nova Scotia; and 24\% (2019) at Saint-Mathieude-Beloeil, Quebec. All sentinel trials, including those that did not conduct plant sampling, reported no O. nubilalis plant injury in the Bt hybrids, with the exception of three locations. Non-Bt plots at Painter, VA, had relatively high levels of ear and stalk damage each year, particularly in 2018 . At this location, $8 \%$ of the Remedy plants expressing Cry1 Ab and Vip3Aa in 2018 and 7\% of the Cry1Ab expressing plants in 2019 showed evidence of O. nubilalis entrance holes and frass. Sentinel plots of BC0805 at Saint-Mathieu-deBeloeil, Quebec, in 2019 also had 5\% of the plants showing husk and shank injury.

\section{Helicoverpa zea Damage to Bt Sweet Corn From 1996 to 2019}

To further evaluate the overall changes in amount of damage to each Bt sweet corn hybrid, the 2017-2019 results were compared with previously reported data from paired Bt and non-Bt sweet corn trials (extracted from Dively et al. 2016, Burkness et al. 2010, and Shelton et al. 2013). Figure 2 illustrates changes over time in percentage of ears damaged by $\mathrm{H}$. zea in Cry1 Ab sweet corn relative to the non-Bt isoline. The 26 trials during 1996-2003 represent the baseline damage to the Cry1Ab hybrid since the trait was introduced in 1996. Ear damage in non-Bt plots averaged $69.8 \% \pm 3.5 \mathrm{SE}$ and ranged from 36 to $99 \%$, reflecting the variation in H. zea infestations across years and trial locations. Ear damage in the Bt plots averaged $12.6 \%$ $\pm 2.3 \mathrm{SE}$ and was positively correlated with the levels of damage in the paired non-Bt plots $(r=0.73, P<0.001)$. Pairing of plots by trial (indicated by the connecting lines) differed by an average of $57.2 \%$ (95\% CL: 52-62). The estimated phenotypic frequency of resistance (ratio of mean densities of $H$. zea larvae per Bt ear relative to larval densities per non-Bt ear) was 0.28 , meaning that about one-third of the H. zea were able to survive expression of Cry1Ab toxin, allowing some level of silk tissue and kernel consumption.

Thirty-three trials during 2004-2010 showed an increase in damaged ears in the Bt plots, averaging 52.0\% $\pm 4.2 \mathrm{SE}$ compared with $87.7 \% \pm 2.3 \mathrm{SE}$ in non-Bt plots. Starting at this time period, ear protection by Cry $1 \mathrm{Ab}$ became more variable, and several trials showed similar levels of ear damage in both Bt and non-Bt plots (denoted by more horizontal connecting lines). The mean difference declined

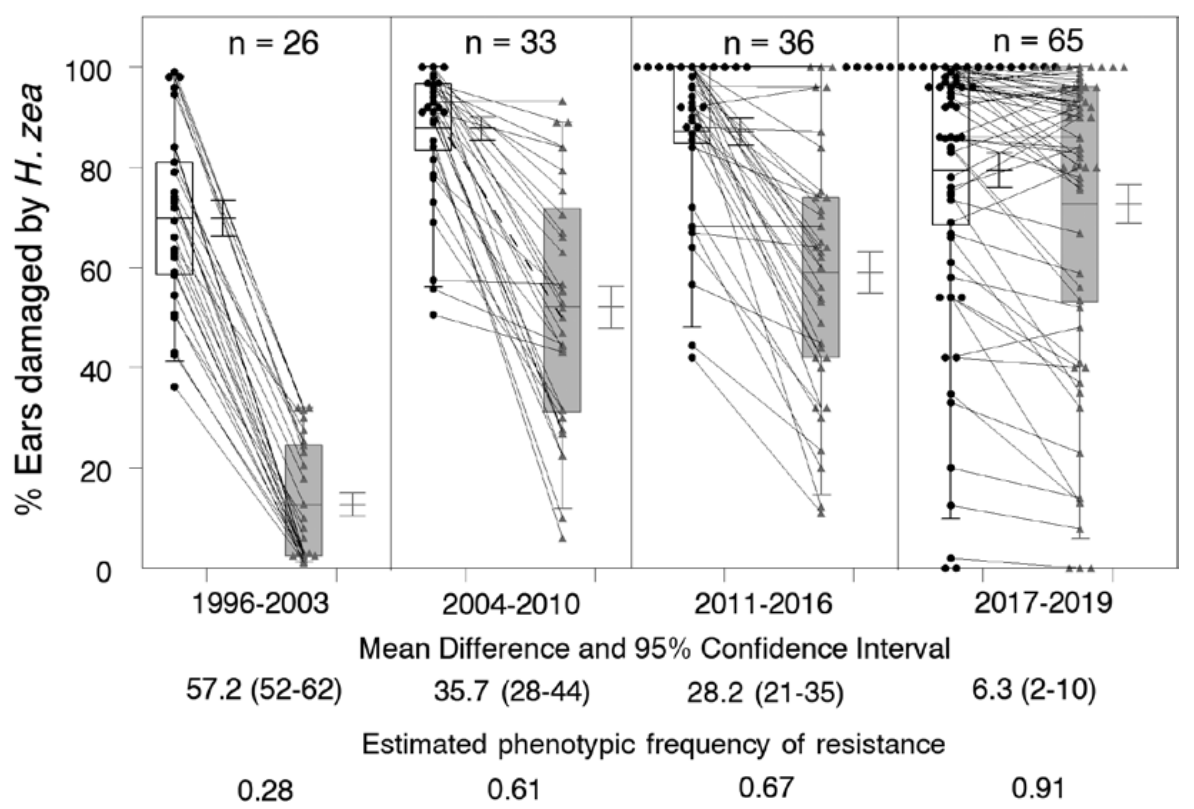

0.28

0.61

0.67

Fig. 2. Percent ears damaged by Helicoverpa zea in paired sentinel plots of Cry1Ab expressing sweet corn and its non-Bt isoline over time. Individual data (non-Bt isoline-circles, Bt-triangles) from multiple trials are given for four time periods after commercial introduction of the Cry1Ab trait. Each box plot depicts the 25 and $75 \%$ percentile range of individual data, median, mean $\pm \mathrm{SE}$, connecting lines linking each paired trial, and $n=$ number of trials. The mean difference between paired plots and $95 \% \mathrm{CL}$ are given for each time period. Nonoverlapping $95 \% \mathrm{CL}$ between time periods indicate a significant change in amount of damage. Also given are the estimated phenotypic frequencies of resistance for each time period defined as the ratio of mean densities of $H$. zea larvae per $\mathrm{Bt}$ ear relative to larval densities per non-Bt ear. 
to $35.7 \%$ (95\% CL: $28-44$ ), which was significantly different from the baseline response of the previous time period $(P<0.001, t$-test $)$. The phenotypic resistance frequency of 0.61 showed a doubling in the densities of surviving larvae in Bt ears relative to densities in non-Bt ears.

Data from 36 trials during 2011-2016 showed no change in H. zea damage in non-Bt plots and only a small increase in the phenotypic frequency of resistance compared with the previous time period. Mean difference between paired plots decreased to $28.2 \%$ (95\% CL: 21-35) but was not statistically different from the previous period $(P=0.110, t$-test). However, results of the 65 trials of the monitoring network conducted during 2017-2019 in Fig. 2 show a significant decline in $H$. zea susceptibility to the Cry $1 \mathrm{Ab}$ toxin. Mean ear damage $(79.4 \% \pm 3.5 \mathrm{SE})$ in non-Bt plots was not significantly different from previous time periods, whereas $H$. zea damage was significantly higher in the Cry1 Ab plots $(72.6 \% \pm 3.8$ $\mathrm{SE})$, with many trials reporting damage levels equal to or higher than levels in adjacent non-Bt plots. The mean difference in percentage ears damaged significantly dropped to $6.3 \%$ (95\% CL: 2-10) compared with the previous time period $(P=0.030, t$-test $)$, and estimated phenotypic frequency of resistance increased to 0.91 , suggesting a major increase in the Cry1Ab resistant gene frequency in $H$. zea populations.

Figure 3 displays changes in $H$. zea ear damage in Cry1A.105+Cry2Ab2 sweet corn relative to the non-Bt isoline over three time periods. These pyramided $\mathrm{Bt}$ traits in sweet corn were commercially available starting in 2010, and the baseline damage during the first four years (2010-2013) is represented by 31 trials of Performance Series hybrids (various hybrids including Obsession II) paired with non-Bt isolines. During this period, Bt plots averaged $18.4 \% \pm 2.1 \mathrm{SE}$ damaged ears compared with $87.6 \% \pm 2.0 \mathrm{SE}$ in the non-Bt plots, with an overall difference of $68.5 \%$ (95\% CL: 62-74). Comparable to the Cry $1 \mathrm{Ab}$ sweet corn, the estimated phenotypic frequency of resistance of 0.19 indicates that Cry1A.105+Cry2Ab2 did not provide a high dose for $H$. zea, when first introduced commercially. Moreover, the effectiveness of these toxins against $H$. zea became more variable starting in 2014 and significantly declined during 2014-2016. Helicoverpa zea damage in Bt plots increased to an average of $39.0 \% \pm 7.3 \mathrm{SE}$, which resulted in a significant decrease in the mean difference between paired plots, averaging $47.2 \%$ (95\% CI: 35-60) and a doubling of the phenotypic resistance frequency (0.41). Amount of damage continued to increase during 2017-2019 as evident by many sentinel pairs of Bt and non-Bt plots with near equal levels of ear damage. During this period, mean difference significantly dropped to $15.8 \%$ (95\%CI: 11-21) and the densities of larvae found in Bt ears more than doubled those found during the previous period, resulting in a phenotypic frequency of resistance of 0.86 .

Figure 4 displays $H$. zea ear damage in Cry1Ab+Vip3A sweet corn (Remedy) across four time periods. Here, we show the baseline damage to the pyramided toxins reported from 27 trials conducted in MD and MN during 2007-2014 compared with individual trial data of each year of the monitoring network. Only 26 of the 3,043 Bt ears $(0.95 \% \pm 0.27 \mathrm{SE})$ sampled during $2007-2014$ showed evidence of $H$. zea kernel injury, with a total of 17 second instars observed alive with minor feeding on a few tip kernels. In comparison, $86.1 \% \pm 4.2 \mathrm{SE}$ of the 1,317 ears sampled in the non-Bt isoline plots were heavily damaged with an average of 0.87 larvae per damaged ear. Damage to Cry1Ab+Vip3A sweet corn during the monitoring network did not significantly change from the baseline level, with the percentage of damaged ears ranging from 0.6 to $1 \%$ and no significant mean differences between paired plots among time periods. However, as indicated in Table 1 , the mean number of larvae per damaged ear $\left(F_{(2,72)}=3.924, P=0.024\right)$ and proportion of larvae $\geq$ fourth instars $\left(\chi^{2}=20.06, P<0.001\right)$ significantly increased in the Cry1Ab+Vip3A ears in 2019. Furthermore, the phenotypic frequency of resistance shows an increase from 0.006 during the baseline years to 0.024 in 2018 and 0.014 in 2019.

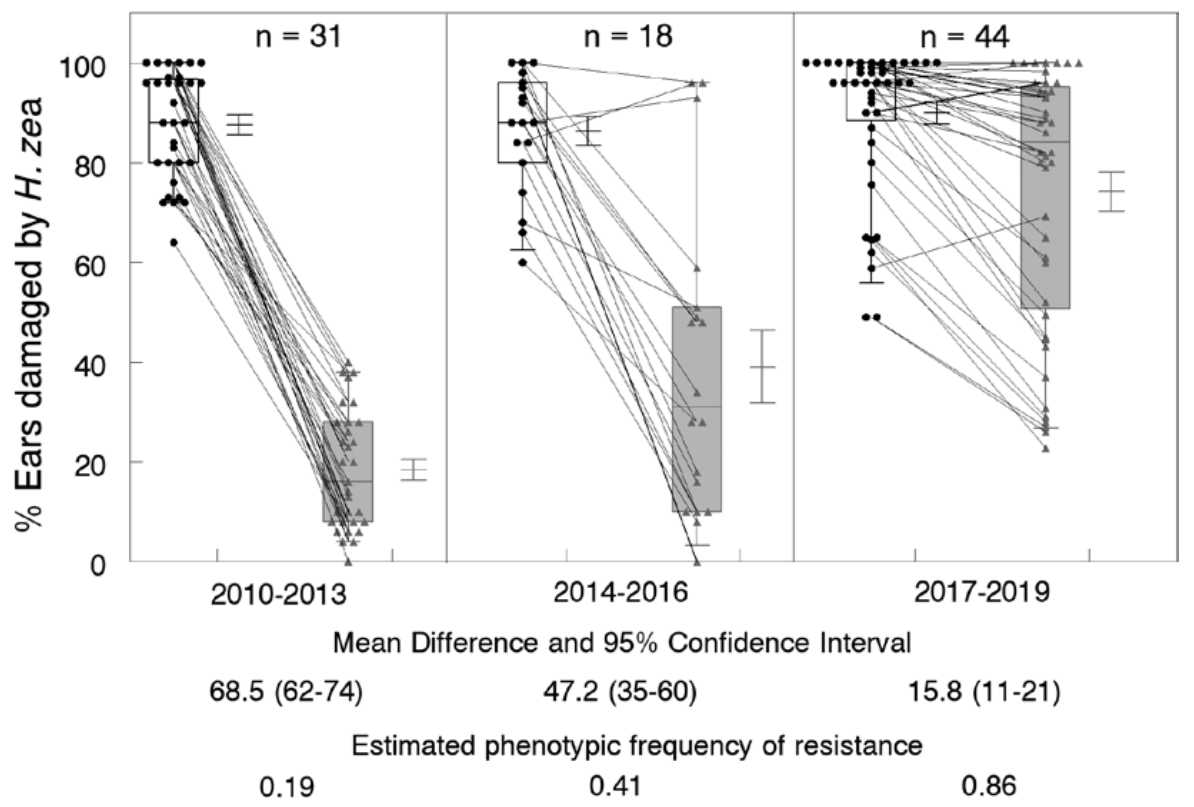

Fig. 3. Percentage of ears damaged by Helicoverpa zea in paired sentinel plots of Cry1A.105+Cry2Ab2 expressing sweet corn (Performance Series ‘Obsession $\mathrm{II}^{\prime}$ ) and its non-Bt isoline over time. Individual data (non-Bt isoline-circles, Bt-triangles) from multiple trials are given for 3 time periods after commercial introduction of the pyramided traits. Each box plot depicts the 25 and $75 \%$ percentile range of individual data, median, mean \pm SE, connecting lines linking each paired trial, and $n=$ number of trials. The mean difference between paired plots and $95 \% \mathrm{CL}$ are given for each time period. Nonoverlapping $95 \% \mathrm{CL}$ between time periods indicate a significant change in amount of damage. Also given are the estimated phenotypic frequencies of resistance for each time period defined as the ratio of mean densities of $H$. zea larvae per Bt ear relative to larval densities per non-Bt ear. 


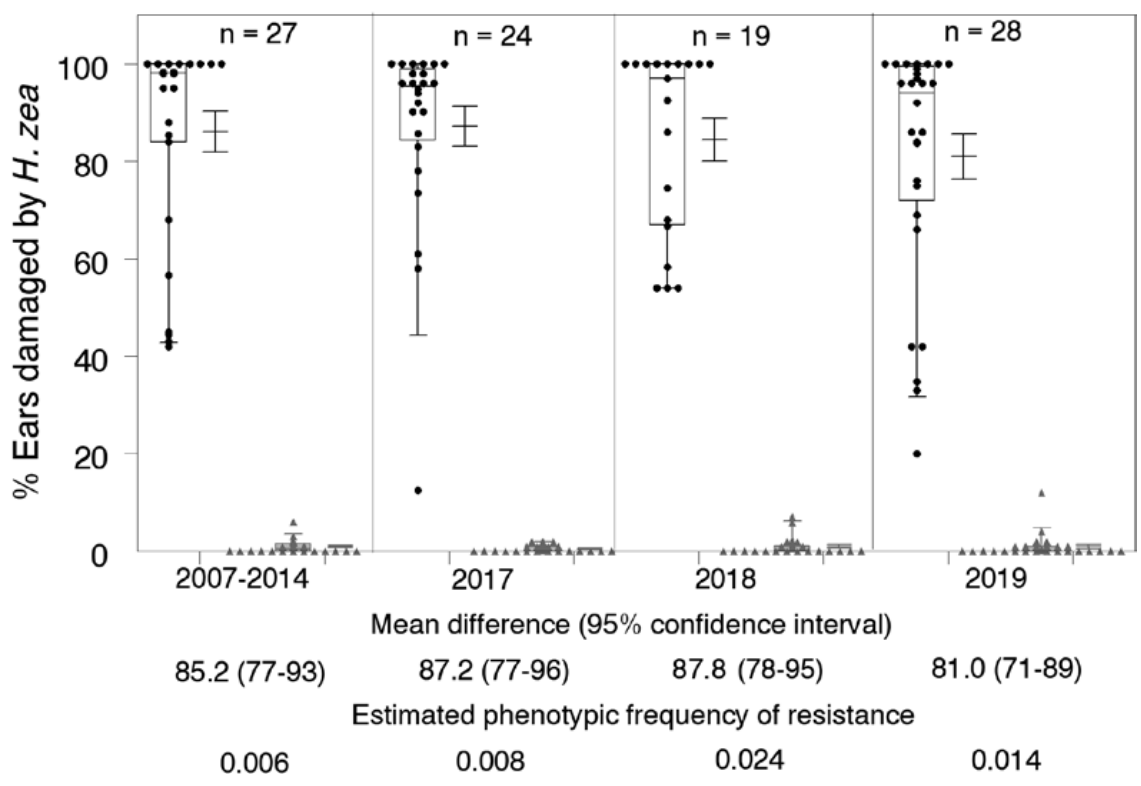

Fig. 4. Percent ears damaged by Helicoverpa zea in paired sentinel plots of Attribute II sweet corn (Cry1Ab+Vip3A) and its non-Bt isoline over time. Individual data (non-Bt isoline-circles, Bt-triangles) from multiple trials are given for four time periods after commercial introduction of the Vip3A trait. Each box plot depicts the 25 and $75 \%$ percentile range of individual data, median, and mean \pm SE. Each box plot depicts the 25 and $75 \%$ percentile range of individual data, median, mean $\pm \mathrm{SE}$, and $n=$ number of trials. The mean difference and $95 \% \mathrm{CL}$ are listed for each time period. Overlapping $95 \% \mathrm{CL}$ between time periods indicate no significant change in amount of damage over time. Also given are the estimated phenotypic frequencies of resistance for each time period defined as the ratio of mean densities of Helicoverpa zea larvae per Bt ear relative to larval densities per non-Bt ear.

\section{Discussion}

Most of our 2017-2019 Bt sweet corn sentinel plots experienced high H. zea pressure, as evident by $>75 \%$ of the non-Bt isoline ears damaged by $H$. zea in 50 of the 69 trials. Differences in infestation levels among trial locations most likely reflect variable levels of incoming H. zea moths via long-distance migration (Westbrook et al. 1995, Seymour et al. 2016, Perera et al. 2020) mixed with moths sourced from local overwintered populations. We also evaluated damage by other key lepidopteran pests. Infestations of $S$. frugiperda were highly scattered across trial locations, with kernel damage in non-Bt ears reported in only 16 of the 69 trials, and infestation levels were not consistently high enough to detect any changes in $S$. frugiperda susceptibility to the toxins. Because this insect only successfully overwinters in the most southern regions of the United States. (below $28^{\circ}$ $\mathrm{N}$ latitude), pest pressure depends on the number and timing of migrant moths reaching trial locations each year (Mitchell et al. 1991, Westbrook et al. 2019). Late plantings of sweet corn are highly attractive to $S$. frugiperda and can serve as an effective sentinel tool to detect changes in susceptibility, but additional trial locations in the southern states where this pest is more prevalent would be required for future monitoring.

Infestations of $\mathrm{O}$. nubilalis normally reach economically damaging levels in non-Bt sweet corn, particularly in late plantings if untreated (Mason et al. 2018). However, only 26 of the 69 trials reported $O$. nubilalis injury in the isoline plots, with only a few locations experiencing relatively high levels of ear and plant damage. The absence of $O$. nubilalis infestations at most locations is not surprising, because the high adoption of Bt field corn has resulted in significant regional suppression of this pest (Hutchison et al. 2010, Dively et al. 2018). Consequently, landscapes surrounding trials with higher infestations probably contained less Bt field corn acreage (less population suppression) or had other suitable host plants to sustain O. nubilalis populations. All trials reported no O. nubilalis damage in the Bt hybrids, except for two locations that observed $<10 \%$ of the plants injured in two Bt hybrids. It is questionable whether larvae causing this injury actually survived on the plants, since other $\mathrm{Bt}$ hybrids in these trials showed no evidence of O. nubilalis ear or plant injury. In previous experiments involving small plots of sweet corn, similar injury occurrences were caused by prediapause fifth instars that exited heavily damaged non-Bt plants, moved to adjacent Bt plots, and bored into stalks without lethal intoxication (Bolin et al. 1998; Dively, unpublished data). This could be the reason for the unexpected injury at the two locations; however, resistance development cannot be ruled out (e.g., Smith et al. 2019), and further monitoring and evaluation of $\mathrm{O}$. nubilalis sensitivity to Bt toxins is necessary to confirm these findings.

Most sentinel trials experienced $H$. zea infestations resulting largely from influxes of migrant moths from the South, where populations were likely exposed to selection events in Bt corn and $\mathrm{Bt}$ cotton. Only one Bt sweet corn hybrid prevented economic damage by H. zea; Cry1Ab and Cry1A.105+Cry2Ab2 expressing hybrids provided only 8.1 and $19.2 \%$ overall reduction in ear damage, respectively, compared with $99.3 \%$ reduction by the Cry1A+Vip3Aa hybrid. Of the 30 trials conducted in 2019, 17 trials reported an equal or higher level of damaged ears in the Cry expressing hybrids than damage levels in the adjacent isoline plots. These results provide further evidence of $H$. zea resistance to Cry1 and Cry2 toxins (Dively 2016; Reisig et al. 2018; Yang et al. 2018, 2019). Our sentinel monitoring network was also able to capture an increase in resistance to the Cry toxins over the 3 yr by measuring kernel consumption, larval density, and larval instar. While the percentage of ears damaged did not change, kernel consumption and larval density per ear increased in the Cry1 Ab hybrid and the proportion of late H. zea instars increased in the Cry1A.105+Cry2Ab2 hybrid. This was particularly evident in 2019 when the mean density of surviving larvae per Cry $1 \mathrm{Ab}$ ear was nearly equal to the larval density in adjacent isoline ears, which indicates that many larvae were able to tolerate Cry1 Ab expression. The high larval densities in Bt hybrids 
may also result from suppression of cannibalistic behavior by sublethal intoxication, which could allow a greater number of larvae to survive to later instars in Bt ears. Cannibalism has a major impact on the population dynamics of $H$. zea in corn ears and can cause up to $75 \%$ larval mortality (Stinner et al. 1977, Dial and Adler 1990), and many of our sites detected dead and partially consumed larvae in the non-Bt ears. If Cry toxin expression suppresses cannibalistic behavior but does not kill larvae, it is plausible that a Cry expressing plant could produce the same or even more moths than moths that emerge from a non-Bt plant, which could negatively impact IRM refuge strategies by outnumbering susceptible moths. Corn is a preferred host that readily supports $H$. zea development and survival (Martin et al. 1976, Gore et al. 2003, Reay-Jones 2019), which may further exacerbate this potential issue. Cannibalistic encounters may also help partially resistant larvae survive by providing a nontoxic food that enables them to temporarily escape exposure to Bt toxins; thus, cannibalistic behavior could alter the selective differential between susceptible larvae and those carrying resistance genes (Storer et al. 1999, Horner and Dively 2003). Reay-Jones et al. (2020) reported that Cry expressing field corn still produces fewer and smaller H. zea pupae compared to non-Bt near-isolines, but the reduction in pupal weight has significantly declined from 2014 to 2019. Additional studies are needed to determine whether H. zea larvae emerging from Bt ears can survive to adulthood and mate with the same fitness and reproductive characteristics as adults emerging from non-Bt ears; however, higher $H$. zea survival in $\mathrm{Bt}$ hybrids relative to non-Bt could have serious consequences for IRM strategies.

Although Cry toxins were never high dose for H. zea, susceptibility to Cry-expressing hybrids has clearly changed since the introduction of these toxins, which is evident in field damage data. Increases in ear damage in Cry1 Ab expressing hybrids were detected during 2004-2010 before the consequences of reduced field efficacy were realized by growers. During this period, differences in ear damage between paired Bt and non-Bt plots significantly decreased and the phenotypic frequency of resistance doubled as the ratio of larvae per Bt ear relative to larvae per non-Bt ear. As a consequence, sweet corn growers and seed companies began to report unacceptable levels of ear damage in Cry1Ab expressing sweet corn during the late 2000s (Dively et al. 2016). Our 2017-2019 monitoring data indicate further declines in efficacy, with the mean difference between hybrids significantly dropping to $6.3 \%$ and the phenotypic frequency of resistance increasing to 0.91 . Taken together, this indicates that an UXI event occurred during 2004-2010, followed by a continued decrease in $H$. zea susceptibility to the Cry1Ab toxin. Similarly, the effectiveness of Performance Series sweet corn containing Cry1A.105+Cry2Ab2 toxins started to become more variable in 2014, and overall efficacy significantly declined from 2014 to 2016 , only 4 yr after its commercial introduction in 2010. Parallel to the decline in efficacy, the phenotypic frequency of resistance doubled during each of the last two time periods, suggesting significant increases in the resistant allele frequency. The change in $H$. zea susceptibility to the Cry1A.105+Cry2Ab2 toxins occurred over a relatively short period compared with the Cry $1 \mathrm{Ab}$ toxin. A combination of factors, particularly non-high dose expression, reduced refuge size, cross resistance between Cry proteins, and increased selection pressure from new pyramided Bt crops expressing the same toxins likely contributed to the rapid development of resistance (Tabashnik and Carrière 2017, Reisig and Kurtz 2018, Yang et al 2019). Presently, Attribute (commercialized in 1998) and Performance Series (commercialized in 2010) sweet corn provides 80 to $90 \%$ less effective control of $H$. zea, than it did when first commercialized.
Ultimately, our sentinel monitoring approach provided evidence for $H$. zea field-evolved resistance starting in 2004 for Cry1 Ab and in 2014 for Cry1A.105+Cry2Ab2. In addition, dose-response bioassays detected resistance to Cry1A.105 and Cry2Ab2 in multiple H. zea populations in 2017, which was also supported by field trial results (Kaur et al. 2019). Yet, registrants' diagnostic dose diet bioassay approach has not detected any significant change in $H$. zea susceptibility to the Cry toxins relative to the known range of baseline susceptibility (USEPA 2020). We believe that a major reason for the lack of detection is that all larvae for laboratory bioassays were collected from non-Bt host plants, not surviving larvae from the Bt crops. In addition, $H$. zea resistance was not detected via diet bioassays because the diagnostic dose may have been too high, and because the protein to carbohydrate ratio was suboptimal (Deans et al. 2016, 2017). Thus, for several reasons, regulatory follow-up and resistance mitigation actions were not triggered. Unfortunately, it is probably too late to implement any management action to reduce $H$. zea resistance to the Cry toxins, but there are still opportunities for improving IRM and resistance monitoring strategies to delay resistance to the highly efficacious Vip3A toxin (Reisig and Kurtz 2018).

The pyramided Cry1Ab+Vip3A toxins still provide near $100 \%$ control of $H$. zea, even under very high population pressure at most trial locations. In total, we found 78 live larvae in 67 damaged ears of 9,369 ears sampled (0.72\% damaged ears) across 69 trials during 2017-2019. Overall kernel injury ranged from 0.002 to $0.007 \mathrm{~cm}^{2}$ per ear. Previous studies have shown that field corn containing Vip3A provides excellent protection against $H$. zea ear damage (Yang et al. 2015, Reay-Jones et al. 2016, Bilbo et al. 2018, Reisig and Kurtz 2018, Yang et al. 2019); however, the range of kernel injury per ear reported in these studies has been consistently higher than levels reported in Vip3A sweet corn. For example, Yang et al. (2019) reported kernel injury averaging $1.3 \mathrm{~cm}^{2}$ per ear in Leptra corn expressing Cry1Ab, Cry1F, and Vip3A, and 93\% reduction of ear damage compared to non-Bt hybrids. They also show some evidence of tolerance to Vip3A based on laboratory bioassays of $H$. zea populations collected in the South. The higher levels of ear and kernel damage reported in Vip3A field corn could be attributed to different expression levels of the toxin, particularly in silk tissue, and the maturation stage of kernels and silk tissue when damage was recorded. Populations also experience heavy selection pressure in the South because both corn and cotton expressing Vip3A are grown (Yang et al. 2019).

Our results in Vip3A sweet corn indicate the number of live larvae per damaged ear, the proportion reaching fourth instars, and the phenotypic frequency of resistance over the $3 \mathrm{yr}$ of the monitoring network is slowly increasing. In particular, the number of larvae per damaged ear more than tripled in 2019, mainly due to an unusually high number of live larvae recorded at the Catawba, VA, and Lubbock, TX locations (see Supp Table 2). Unfortunately, ears with these UXI levels were not checked for Vip3A expression. The low ratios of larvae per Bt ear relative to larvae per non-Bt ear (ranging from 0.006 to 0.024 ) corroborate the findings by Burkness et al. (2010) that Vip3A toxin expression provides a near high dose against $H$. zea under field conditions. Statistically, it was not possible to detect differences in phenotypic frequencies among time periods due to the highly skewed distribution of data (most trials reported no larvae in Vip3A ears). Moreover, the frequencies are most likely overestimated because we assumed that any live larvae in a Bt ear would survive to contribute to the gene pool in the next generation. Still, these findings taken together with the increased kernel injury reported by Yang et al. (2019) and documentation of Vip3A 
resistance alleles in field populations in Texas (Yang et al. 2020), suggest that early stages of resistance to this important toxin are occurring in $H$. zea populations. Therefore, there is an urgent need for improvements in IRM strategies to proactively manage $H$. zea resistance to the Vip3A toxin (Reisig and Kurtz 2018) and effective resistance monitoring approaches capable of detecting UXI early must be used. For example, the development of improved genotypic resistance monitoring through molecular genetics or 'omics' technologies as well as clear genotypic and phenotypic resistance thresholds will improve resistance monitoring (USEPA 2018). Until these advances have been made, resistance monitoring will continue to rely on field- and laboratory-based Bt resistance monitoring strategies. To effectively detect resistance, field and laboratory assays must be conducted according to their respective best practices (Table 2). Diet bioassays and sentinel plots are complimentary approaches that provide different information with respect to Bt resistance. Therefore, the most robust data set results when these approaches are used in combination; however, that can be cost and labor prohibitive. When used alone, both approaches have their strengths and limitations (Table 2); however, sentinel plots likely will detect phenotypic resistance earlier.
Our study demonstrated that the sentinel plot approach can effectively monitor resistance in target pest populations by measuring differences in ear damage and larval infestations between isogenic pairs of non-Bt and Bt plots. Sweet corn is a better sentinel host plant than field corn for detecting changes in susceptibility of H. zea populations for several reasons. First, gravid adults are more attracted to the late plantings of sweet corn, resulting in significantly higher ear infestations than field corn. Higher infestation rates expose a larger number of individuals to the toxin and increase the chances of detecting susceptibility changes. Second, available Bt sweet corn hybrids express Cry1Ab, Cry1A.105, Cry2Ab2, and Vip3A at higher levels of expression during the silking and ear development stages than field corn as measured by diet bioassays with lyophilized tissue (Dively, unpublished data) and assessment of kernel damage at the milk stage, prior to the majority of larvae exiting the ear to pupate, increases the chances of identifying and recording the highest densities of larvae exposed to the highest toxin expression. Sampling Bt field corn during later maturity stages can be problematic because larvae are more likely to consume senesced silk and cob tissue with lower levels of Bt expression. In addition, when sampling later ear maturity in field corn, larvae are less likely to be present making

Table 2. Comparison of the proposed field-based sentinel plot approach to a laboratory-based diet bioassay for monitoring resistance to Bt toxins

Paired sentinel plots

Best practices

- Sweet corn hybrids expressing Bt toxins planted side by side with true isoline pairs.

- Late season plantings at same locations each year and timed to maximize overlap with later moth flights

- Hybrids planted in order of decreasing efficacy to reduce the risk of false positives.

- Plots managed according to production best practices for more consistent Bt protein content

- Each hybrid sampled when the highest number of larvae are present (Bt slightly later than non-Bt).

- Bt expression confirmed for plants with damage outliers

Response variables: \% infestation, ear damage, larval density and instar Information gained

- Background pest pressure as well as field efficacy (field damage directly measured)

- Phenotypic resistance, a consistent decline

in efficacy over multiple years and sites evidences field-evolved resistance

Strengths

- Exposes a large field population to fieldrelevant doses

- Allows for analysis of efficacy differences between paired plots.

- Gathers data about multiple target pests simultaneously

- Monitors same population from year to year at multiple sites

- Relatively low labor and materials costs
Overwintering and migration patterns may impact population genetic structure from year to year

- Difficult to link phenotypic data to allele frequency without genomics work
Diet bioassays

Best practices

- Populations collected from Bt expressing plants and targeted towards later generations that have experienced within season $\mathrm{Bt}$ selection pressure in earlier crops

- Larval development assays require laboratory rearing to at least $\mathrm{F}_{1}$ generation and $\mathrm{F}_{2}$ sib-mated populations can be more effective in detecting resistance

- Standardized protocols (to be developed) with purified toxins and a consistent susceptible population better ensures comparability across studies (specific to each pest assayed)

- Diet optimized for success of both field and susceptible populations (specific to each pest assayed)

Response variables: \% mortality, larval growth and instar

Information gained

- Able to categorize phenotypic resistance

- Depending on approach: $\mathrm{LD}_{50}$ or $\mathrm{LC}_{50}$, resistance ratio, resistance allele frequency

- Relative to baseline susceptibility and/or susceptible population
Strengths

- Quantitative genetic theory enables linkage of phenotype to genetics under controlled conditions

- Allows for analysis of the resistance allele frequency

- Well-established protocols and analyses that answer a wide variety of questions related to resistance

Limitations

- Difficult to collect and rear sufficient individuals from Bt plants prior to a decline in field efficacy

- False negatives occur when resistance genotypes are lost during the rearing process

- Some pests are recalcitrant to laboratory manipulation

- Relatively high labor and materials costs

Information summarized from Venette et al. (2000), Tabashnik et al. (2014), Trtikova et al. (2015), and USEPA (2018) as well as authors' experiences. 
injury difficult to separate by lepidopteran species. Unlike field corn, true isogenic hybrids are available for each Bt sweet corn hybrid to be paired side-by-side, which lowers the risk of UXI 'false positives' resulting from mismatches in pest pressure and allows for paired statistical analysis of differences between plots of multiple trials. This is an important consideration when estimating the phenotypic frequency of resistance, which assumes that sentinel pairs of Bt and isogenic hybrids are equally likely to become infested and larvae are subject to the same rate of mortality due to other mortality factors (Venette et al. 2000). Without true isogenic pairs, differences in plant attractiveness to gravid females, timing of silking periods, and ear architecture can affect these assumptions. Finally, an additional advantage of sentinel plots is the opportunity to simultaneously monitor more than one target pest and to collect larvae for follow-up laboratory bioassays. Pyramided Cry1Ab+Vip3A sweet corn may be a better sentinel plant than hybrids expressing Cry1 $\mathrm{Ab}$ alone for detecting shifts in O. nubilalis susceptibility to the Cry1 Ab toxin because Vip3A has no effect on this pest (Estruch et al. 1996, Chakrabarty et al. 2020) and the absence of the more competitive H. zea larvae allows more corn borers to survive and become exposed to Cry1 Ab expression in the kernels. However, if sentinel plots are to be used as a monitoring tool, we need standardized thresholds that define UXI and/or a phenotypic frequency of larvae in Vip3A expressing corn that would trigger follow-up investigations or appropriate mitigation action (USEPA 2018).

To maximize the chances for sentinel sweet corn monitoring to detect shifts in susceptibility, we recommend that trials be planted later in the growing season in the Southern states, so that silking occurs after $\mathrm{H}$. zea has experienced a generation of selection in $\mathrm{Bt}$ field corn. Trials should also be conducted in northern locations, where O. nubilalis is more prevalent and H. zea infestations result primarily from migrant moths coming from southern populations preselected for resistance in Bt corn as their larval host. Since H. zea has already developed resistance to Cry toxins, sentinel trials at a minimum need only to include side-by-side plantings of pyramided Cry1Ab+Vip3A sweet corn and the non-Bt isogenic hybrid to monitor changes in susceptibility to the Vip3Aa toxin. Whenever possible, larger sample sizes of ears should be examined to increase the probability of detecting resistant larvae, and ears in each hybrid should be sampled at different times to ensure sampling when the highest number of larvae are present. Data gathered from multiple locations should be pooled by year in order to make inferences about the overall $H$. zea population based on differences in control efficacy and phenotypic frequencies of resistance. The 2018 SAP addressed potential constraints relating to the cost and ability to coordinate and manage the sentinel monitoring approach (USEPA 2018). As demonstrated in this study, sentinel sweet corn plots can be implemented effectively through a network of land-grant cooperators and research farm facilities working together with registrants of Bt crops to provide year-to-year monitoring. We therefore believe that the costs of a sweet corn sentinel network may be less expensive than the monitoring approach currently used by registrants, and the information generated has the best chance of detecting early stages of $H$. zea resistance to Vip3A, allowing for timely improvements in IRM strategies in order to maintain the sustainability of this important technology.

\section{Supplementary Data}

Supplementary data are available at Journal of Economic Entomology online.

\section{Acknowledgments}

We gratefully acknowledge the technical assistance of T. Patton, M. Dimoc, and V. Yurchak (MD); J. Jasinski (OH); B. Lingbeek (PA); J. D. Johnson and J.J. Barrett (WV); R. Harding, M. Zuefle, K. Jackson, F. Zaman, and S. Menasha (NY); J. Deidesheimer, B. Cissel, and J. Whalen (DE); P. Blevins, A. Taylor and S. Malone (VA); T. Phibbs, I. DeSchiffart, R. VandenBroek, N. Hitsman, and T. St.Georges-Fingler (Ontario); and M. Lennon and T. Teal (SC). We acknowledge the help of A. Leslie (MD) for the development of Fig. 1. We thank the research farm managers at each trial location for establishing and maintaining the paired plantings of $\mathrm{Bt}$ and non-Bt sweet corn. We particularly thank J. Cassidy (Syngenta) and M. Bourguignon (Seminis) for providing sweet corn seed. As for funding sources, most cooperators volunteered their time without external funding; however, we specifically acknowledge partial funding from the Friends of Long Island Horticulture, Hatch Multistate Research Fund (NC, no. 1006646; MD, no. 0095671). and National Institute of Food and Agriculture, Crop Protection and Pest Management Program, Extension Implementation Program (DE, no. 2017-70006-27286; MN, no. 2017-70006-27278).

\section{References Cited}

Andow, D. A., S. G. Pueppke, A. W. Schaafsma, A. J. Gassmann, T. W. Sappington, L. J. Meinke, P. D. Mitchell, T. M. Hurley, R. L. Hellmich, and R. P. Porter. 2016. Early detection and mitigation of resistance to $\mathrm{Bt}$ maize by western corn rootworm (Coleoptera: Chrysomelidae). J. Econ. Entomol. 109: 1-12.

Bell, J. R., E. C. Burkness, A. E. Milne, D. W. Onstad, M. Abrahamson, K. L. Hamilton, and W. D. Hutchison. 2012. Putting the brakes on a cycle: bottom-up effects damp cycle amplitude. Ecol. Lett. 15: 310-318.

Bilbo, T. R., F. P. F. Reay-Jones, D. D. Reisig, F. R. Musser, and J. K. Greene. 2018. Effects of Bt corn on the development and fecundity of corn earworm (Lepidoptera: Noctuidae). J. Econ. Entomol. 111: 2233-2241.

Bilbo, T. R., F. P. F. Reay-Jones, D. D. Reisig, and J. K. Greene. 2019. Susceptibility of corn earworm (Lepidoptera: Noctuidae) to Cry1A.105 and Cry2Ab2 in North and South Carolina. J. Econ. Entomol. 112: 1845-1857.

Blanco, C. A., M. Portilla, J. L. Jurat-Fuentes, J. F. Sánchez, D. Viteri, P. VegaAquino, A. P. Terán-Vargas, A. Azuara-Domínguez, J. D. López, Jr., R. Arias, et al. 2010. Susceptibility of isofamilies of Spodoptera frugiperda (Lepidoptera: Noctuidae) to Cry1Ac and Cry1Fa proteins of Bacillus thuringiensis. Southwest. Entomol. 35: 409-415.

Bolin, P. C., W. D. Hutchison, D. A. Andow, and K. R. Ostlie. 1998. Monitoring for European corn borer (Lepidoptera: Crambidae) resistance to Bacillus thuringiensis: logistical considerations when sampling larvae. J. Agric. Urban Entomol. 15: 231-238.

Buntin, G. D., J. N. All, R. D. Lee, and D. M. Wilson. 2004. Plant-incorporated Bacillus thuringiensis resistance for control of fall armyworm and corn earworm (Lepidoptera: Noctuidae) in corn. J. Econ. Entomol. 97: 1603-1611.

Burkness, E. C., G. Dively, T. Patton, A. C. Morey, and W. D. Hutchison. 2010. Novel Vip3A Bacillus thuringiensis (Bt) maize approaches high-dose efficacy against Helicoverpa zea (Lepidoptera: Noctuidae) under field conditions: Implications for resistance management. GM Crops. 1: 337-343.

Carrière, Y., C. Ellers-Kirk, M. Sisterson, L. Antilla, M. Whitlow, T. J. Dennehy, and B. E. Tabashnik. 2003. Long-term regional suppression of pink bollworm by Bacillus thuringiensis cotton. Proc. Natl. Acad. Sci. U. S. A. 100: 1519-1523.

Carrière, Y., J. A. Fabrick, and B. E. Tabashnik. 2016. Can pyramids and seed mixtures delay resistance to Bt crops? Trends Biotechnol. 34: 291-302.

Carroll, M. W., G. Head, and M. Caprio. 2012. When and where a seed mix refuge makes sense for managing insect resistance to Bt plants. Crop Prot. 38: 74-79.

Chakrabarty, S., M. Jin, C. Wu, P. Chakraborty, and Y. Xiao. 2020. Bacillus thuringiensis vegetative insecticidal protein family Vip3A and mode of action against pest Lepidoptera. Pest Manage. Sci. 76: 1612-1617. 
Davis, P. M., and D. W. Onstad. 2000. Seed mixtures as a resistance management strategy for European corn borers (Lepidoptera: Crambidae) infesting transgenic corn expressing Cry1Ab protein. J. Econ. Entomol. 93: 937-948.

Deans, C. A., G. A. Sword, and S. T. Behmer. 2016. Nutrition as a neglected factor in insect herbivore susceptibility to Bt toxins. Curr. Opin. Insect Sci. 15: 97-103.

Deans, C. A., S. T. Behmer, A. E. Tessnow, P. Tamez-Guerra, M. Pusztai-Carey, and G. A. Sword. 2017. Nutrition affects insect susceptibility to Bt toxins. Sci. Rep. 7: 39705

Dial, C. I., and P. H. Adler. 1990. Larval behavior and cannibalism in Heliothis zea (Lepidoptera: Noctuidae). Ann. Entomol. Soc. Am. 83:258-263.

Dively, G. P., P. D. Venugopal, and C. Finkenbinder. 2016. Field-evolved resistance in corn earworm to Cry proteins expressed by transgenic sweet corn. PLoS One. 11: e0169115.

Dively, G. P., P. D. Venugopal, D. Bean, J. Whalen, K. Holmstrom, T. P. Kuhar, H. B. Doughty, T. Patton, W. Cissel, and W. D. Hutchison. 2018. Regional pest suppression associated with widespread Bt maize adoption benefits vegetable growers. Proc. Natl. Acad. Sci. U. S. A. 115: 3320-3325.

Edgerton, M. D., J. Fridgen, J. R. Anderson, Jr., J. Ahlgrim, M. Criswell, P. Dhungana, T. Gocken, Z. Li, S. Mariappan, C. D. Pilcher, et al. 2012. Transgenic insect resistance traits increase corn yield and yield stability. Nat. Biotechnol. 30: 493-496.

Estruch, J. J., G. W. Warren, M. A. Mullins, G. J. Nye, J. A. Craig, and M. G. Koziel. 1996. Vip3A, a novel Bacillus thuringiensis vegetative insecticidal protein with a wide spectrum of activities against lepidopteran insects. Proc. Natl. Acad. Sci. U. S. A. 93: 5389-5394.

Farias, J. R., D. Andow, R. J. Horikoshi, R. J. Sorgatto, P. Fresia, A. C. dos Santos, and C. Omoto. 2014. Field-evolved resistance to Cry1F maize by Spodoptera frugiperda (Lepidoptera: Noctuidae) in Brazil. Crop Protection. 64: 150-158.

Gore, J., B. R. Leonard, and R. H. Jones. 2003. Influence of agronomic hosts on the susceptibility of Helicoverpa zea (Boddie) (Lepidoptera: Noctuidae) to genetically engineered and non-engineered cottons. Environ. Entomol. 32: 103-110.

Gould, F. 1998. Sustainability of transgenic insecticidal cultivars: integrating pest genetics and ecology. Annu. Rev. Entomol. 43: 701-726.

Horner, T. A., and G. P. Dively. 2003. Effect of MON810 Bt field corn on Helicoverpa zea (Lepidoptera: Noctuidae) cannibalism and its implications to resistance development. J. Econ. Entomol. 96: 931-934.

Huang, F., J. A. Qureshi, R. L. Meagher, Jr., D. D. Reisig, G. P. Head, D. A. Andow, X. Ni, D. Kerns, G. D. Buntin, Y. Niu, et al. 2014. Cry1F resistance in fall armyworm Spodoptera frugiperda: single gene versus pyramided Bt maize. PLoS One. 9: e112958.

Hutchison, W. D., E. C. Burkness, P. D. Mitchell, R. D. Moon, T. W. Leslie, S. J. Fleischer, M. Abrahamson, K. L. Hamilton, K. L. Steffey, M. E. Gray, et al. 2010. Areawide suppression of European corn borer with Bt maize reaps savings to non-Bt maize growers. Science. 330: 222-225.

Kaur, G., J. Guo, S. Brown, G. P. Head, P. A. Price, S. Paula-Moraes, X. Ni, M. Dimase, and F. Huang. 2019. Field-evolved resistance of Helicoverpa zea (Boddie) to transgenic maize expressing pyramided Cry1A.105/ Cry2Ab2 proteins in northeast Louisiana, the United States. J. Invertebr. Pathol. 163: 11-20.

Koziel, M. G., G. L. Beland, C. Bowman, N. B. Carozzi, R. Crenshaw, L. Crossland, J. Dawson, N. Desai, M. Hill, S. Kadwell, et al. 1993. Field performance of elite transgenic maize plants expressing an insecticidal protein derived from Bacillus thuringiensis. Nat. Biotechnol. 11: 194-200.

Li, G., D. Reisig, J. Miao, F. Gould, F. Huang, and H. Feng. 2016. Frequency of Cry1F non-recessive resistance alleles in North Carolina field populations of Spodoptera frugiperda (Lepidoptera: Noctuidae). PLoS One. 11: e0154492.

Lu, Y., K. Wu, Y. Jiang, Y. Guo, and N. Desneux. 2012. Widespread adoption of Bt cotton and insecticide decrease promotes biocontrol services. Nature. 487: 362-365.

Marques, L. H., A. C. Santos, B. A. Castro, V. F. Moscardini, J. Rosseto, O. A. B. N. Silva, and J. M. Babcock. 2019. Assessing the efficacy of Bacillus thuringiensis (Bt) pyramided proteins Cry1F, Cry1A.105, Cry2Ab2, and Vip3Aa20 expressed in Bt maize against lepidopteran pests in Brazil. J. Econ. Entomol. 112: 803-811.
Martin, P. B., P. D. Lingren, and G. L. Greene. 1976. Relative abundance and host preferences of cabbage looper, soybean looper, tobacco budworm, and corn earworm on crops grown in northern Florida. Environ. Entomol. 5: 878-882.

Mason, C. E., M. E. Rice, C. DiFonzo, and R. P. Porter. 2018. European corn borer - ecology and management and association with other corn pests. NCR Publication No. 327. Iowa State University, Ames, IA. https://store. extension.iastate.edu/product/3067

Mitchell, E. R., J. N. McNeil, J. K. Westbrook, J. F. Silvain, B. LalanneCassou, R. B. Chalfant, S. D. Pair, V. H. Waddill, A. Sotomayor-Rios, and F. I. Proshold. 1991. Seasonal periodicity of fall armyworm (Lepidoptera: Noctuidae) in the Caribbean basin and northward to Canada. J. Entomol. Sci. 26:39-50.

Moar, W., R. Roush, A. Shelton, J. Ferré, S. MacIntosh, B. R. Leonard, and C. Abel. 2008. Field-evolved resistance to Bt toxins. Nat. Biotechnol. 26: 1072-4; author reply 1074.

National Academies of Sciences, Engineering, and Medicine (NASEM). 2016. Genetically engineered crops: experiences and prospects. National Academies Press, Washington, DC

Omoto, C., O. Bernardi, E. Salmeron, R. J. Sorgatto, et al. 2016. Field-evolved resistance to Cry1Ab maize by Spodoptera frugiperda in Brazil. Pest Manage. Sci. 72:1727-1736.

Ostrem, J. S., Z. Pan, J. L. Flexner, E. Owens, R. Binning, and L. S. Higgins. 2016. Monitoring susceptibility of Western bean cutworm (Lepidoptera: Noctuidae) field populations to Bacillus thuringiensis Cry1F protein. J. Econ. Entomol. 109: 847-853.

Perera, O. P., H. W. Fescemyer, S. J. Fleischer, and C. A. Abel. 2020. Temporal variation in genetic composition of migratory Helicoverpa zea in peripheral populations. Insects. 11: 463.

Perry, E. D., F. Ciliberto, D. A. Hennessy, and G. Moschini. 2016. Genetically engineered crops and pesticide use in U.S. maize and soybeans. Sci. Adv. 2: e1600850.

Reay-Jones, F. P. F. 2019. Pest status and management of corn earworm (Lepidoptera: Noctuidae) in field corn in the United States. J. Integr. Pest Manage. 10: 19.

Reay-Jones, F. P., and D. D. Reisig. 2014. Impact of corn earworm injury on yield of transgenic corn producing Bt toxins in the Carolinas. J. Econ. Entomol. 107: 1101-1109.

Reay-Jones, F. P., R. T. Bessin, M. J. Brewer, D. G. Buntin, A. L. Catchot, D. R. Cook, K. L. Flanders, D. L. Kerns, R. P. Porter, D. D. Reisig, et al. 2016. Impact of lepidoptera (Crambidae, Noctuidae, and Pyralidae) pests on corn containing pyramided Bt traits and a blended refuge in the Southern United States. J. Econ. Entomol. 109: 1859-1871.

Reay-Jones, F. P. F., T. R. Bilbo, and D. D. Reisig. 2020. Decline in sublethal effects of Bt corn on corn earworm (Lepidoptera: Noctuidae) linked to increasing levels of resistance. J. Econ. Entomol. 113: 2241-2249.

Reisig, D. D. 2017. Factors associated with willingness to plant non-Bt maize refuge and suggestions for increasing refuge compliance. J. Integrat. Pest Manage. 8:1-10.

Reisig, D. D., and R. Kurtz. 2018. Bt resistance implications for Helicoverpa zea (Lepidoptera: Noctuidae) insecticide resistance management in the United States. Environ. Entomol. 47: 1357-1364.

Reisig, D. D., and F. P. Reay-Jones. 2015. Inhibition of Helicoverpa zea (Lepidoptera: Noctuidae) growth by transgenic corn expressing $\mathrm{Bt}$ toxins and development of resistance to Cry1Ab. Environ. Entomol. 44: $1275-1285$.

Reisig, D., A. S. Huseth, J. S. Bacheler, M. Amir Aghaee, L. Braswell, H. J. Burrack, K. Flanders, J. K. Greene, D. A. Herbert, A. Jacobson, et al. 2018. Long term empirical and observational evidence of practical Helicoverpa zea resistance to cotton with pyramided Bt toxins. J. Econ. Entomol. 111: 1824-1833.

Romeis, J., S.E. Naranjo, M. Meissle, and A. M. Shelton. 2019. Genetically engineered crops help support conservation biological control. Biol. Control. 130: $136-154$

Roush, R. T. 1998. Two-toxin strategies for management of insecticidal transgenic crops: can pyramiding succeed where pesticide mixtures have not? Phil. Trans. Royal Soc. Biol. Sci. 353: 1777-86. 
SAS Institute. 2001. PROC user's manual, version 6th ed. SAS Institute, Cary, NC.

Seymour, M., O. P. Perera, H. W. Fescemyer, R. E. Jackson, S. J. Fleischer, and C. A. Abel. 2016. Peripheral genetic structure of Helicoverpa zea indicates asynchronous panmixia. Ecol. Evol. 6: 3198-3207.

Shelton, A. M., D. L. Olmstead, E. C. Burkness, W. D. Hutchison, G. Dively, C. Welty, and A. N. Sparks. 2013. Multi-state trials of Bt sweet corn varieties for control of the corn earworm (Lepidoptera: Noctuidae). J. Econ. Entomol. 106: 2151-2159.

Smith, J. L., M. D. Lepping, D. M. Rule, Y. Farhan, and A. W. Schaafsma. 2017. Evidence for field-evolved resistance of Striacosta albicosta (Lepidoptera: Noctuidae) to Cry1F Bacillus thuringiensis protein and transgenic corn hybrids in Ontario, Canada. J. Econ. Entomol. 110: 2217-2228.

Smith, J. L., Y. Farhan, and A. W. Schaafsma. 2019. Practical resistance of Ostrinia nubilalis (Lepidoptera: Crambidae) to Cry1F Bacillus thuringiensis maize discovered in Nova Scotia, Canada. Sci. Rep. 9: 18247.

Stinner, R. E., J. W. Jones, C. Tuttle, and R. E. Caron. 1977. Population mortality and cyclicity as affected by intraspecific competition. Can. Entomol. 109:879-890.

Storer, N. P., F. Gould, G. G. Kennedy, and J. W. Van Duyn. 1999. Ecology and biology of cotton bollworm in reference to modeling Bt resistance development in a Bt cotton/Bt corn system, pp. 949-952. In Proceedings, 1999 beltwide cotton conferences. National Cotton Council of America, New Orleans, LA.

Storer, N. P., J. M. Babcock, M. Schlenz, T. Meade, G. D. Thompson, J. W. Bing, and R. M. Huckaba. 2010. Discovery and characterization of field resistance to Bt maize: Spodoptera frugiperda (Lepidoptera: Noctuidae) in Puerto Rico. J. Econ. Entomol. 103: 1031-1038.

Tabashnik, B. E., and Y. Carrière. 2017. Surge in insect resistance to transgenic crops and prospects for sustainability. Nat. Biotechnol. 35: 926-935.

Tabashnik, B. E., and Y. Carriere. 2020. Evaluating cross-resistance between Vip and Cry toxins of Bacillus thuringiensis. J. Econ. Entomol. 113: 553561. doi:10.1093/jee/toz308.

Tabashnik, B. E., J. B. Van Rensburg, and Y. Carrière. 2009. Field-evolved insect resistance to Bt crops: definition, theory, and data. J. Econ. Entomol. 102: 2011-2025.

Tabashnik, B. E., T. Brévault, and Y. Carrière. 2013. Insect resistance to Bt crops: lessons from the first billion acres. Nat. Biotechnol. 31: 510-521.

Tabashnik, B. E., D. Mota-Sanchez, M. E. Whalon, R. M. Hollingworth, and Y. Carrière. 2014. Defining terms for proactive management of resistance to Bt crops and pesticides. J. Econ. Entomol. 107:496-507.

Trtikova, M., O. G. Wikmark, N. Zemp, A. Widmer, and A. Hilbeck. 2015. Transgene expression and $\mathrm{Bt}$ protein content in transgenic $\mathrm{Bt}$ maize (MON810) under optimal and stressful environmental conditions. PLoS One. 10: e0123011.
USDA Economic Research Service. 2019. Recent trends in GE adoption 1996-2019. https://www.ers.usda.gov/data-products/adoption-of-genetically-engineeredcrops-in-the-us/recent-trends-in-ge-adoption.aspx. Accessed 28 June 2020.

USEPA. 2018. Resistance in lepidopteran pests to Bacillus thuringiensis (Bt) plant incorporated protectants (PIPs) in the United States. July 2018 SAP meeting | scientific advisory panel | US EPA. https://www.regulations.gov/ document?D=EPA-HQ-OPP-2017-0617-0078. Accessed 28 June 2020.

USEPA. 2020. EPA draft proposal to address resistance risks to Lepidopteran pests of Bt following the July 2018 FIFRA scientific advisory panel recommendation. Memorandum EPA-HQ-OPP-2019-0682-0007. https://www. regulations.gov/document?D=EPA-HQ-OPP-2019-0682-0007

Venette, R. C., W. D. Hutchison, and D. A. Andow. 2000. An in-field screen for early detection and monitoring of insect resistance to Bacillus thuringiensis in transgenic crops. J. Econ. Entomol. 93: 1055-1064.

Westbrook, J. K., R. S. Eyster, W. W. Wolf, P. D. Lingren, and J. R. Raulston. 1995. Migration pathways of corn earworm (Lepidoptera: Noctuidae) indicated by tetroon trajectories. Agric. For. Meteorol. 73:67-87.

Westbrook, J., S. Fleischer, S. Jairam, R. Meagher, and R. Nagoshi. 2019. Multigenerational migration of fall armyworm, a pest insect. Ecosphere. 10(11): e02919.

Wu, K. M., Y. H. Lu, H. Q. Feng, Y. Y. Jiang, and J. Z. Zhao. 2008. Suppression of cotton bollworm in multiple crops in China in areas with Bt toxincontaining cotton. Science. 321: 1676-1678.

Yang, F., D. L. Kerns, B. R. Leonard, I. Oyediran, T. Burn, Y. Niu, and F. Huang. 2015. Performance of Agrisure ${ }^{\circledR}$ Viptera ${ }^{\mathrm{TM}} 3111$ corn against Helicoverpa zea (Lepidoptera: Noctuidae) in seed mixed plantings. Crop Prot. 69: 77-82.

Yang, F., D. Kerns, J. Gore, A. Catchot, G. Lorenz, and S. Stewart. 2017. Susceptibility of field populations of the cotton bollworm in the southern U. S. to four individual Bt proteins, pp. 786-797. In S. Boyd, M. Huffman and A. Sarkissian (eds.), Proceedings of the beltwide cotton conference volume. National Cotton Council, Memphis, TN.

Yang, F., D. Kerns, J. Gore, A. Catchot, D. Cook, F. Musser, G. Lorenz, N. Seiter, S. Stewart, and B. Sebe. 2018. Continuous monitoring of the susceptibility of Helicoverpa zea in the southern U.S. to different Bt technologies. In Proceedings of the 2018 beltwide cotton conferences, San Antonio, TX, 3-5 January 2018.

Yang, F., J. C. Santiago González, J. Williams, D. C. Cook, R. T. Gilreath, and D. L. Kerns. 2019. Occurrence and ear damage of Helicoverpa zea on transgenic Bacillus thuringiensis maize in the field in Texas, U. S. and its susceptibility to Vip3A Protein. Toxins. 11: 102.

Yang, F., J. C. S. González, N. Little, D. Reisig, G. Payne, R. F. Dos Santos, J. L. Jurat-Fuentes, R. Kurtz, and D. L. Kerns. 2020. First documentation of major Vip3Aa resistance alleles in field populations of Helicoverpa zea (Boddie) (Lepidoptera: Noctuidae) in Texas, USA. Sci. Rep. 10: 5867. 